\section{Planejamento participativo em organizações de saúde: o caso do Hospital Geral de Bonsucesso, Rio de Janeiro, Brasil}

\author{
Participatory planning in health organizations: \\ the case of the Bonsucesso General Hospital, \\ Rio de Janeiro, Brazil
}

\author{
1 Escola Nacional de Saúde \\ Pública Sergio Arouca, \\ Fundação Oswaldo Cruz, \\ Rio de Janeiro, Brasil. \\ 2 Diretoria de Planejamento \\ Estratégico, Fundação \\ Oswaldo Cruz, \\ Rio de Janeiro, Brasil. \\ 3 Instituto de Medicina \\ Social, Universidade do \\ Estado do Rio de Janeiro, \\ Rio de Janeiro, Brasil. \\ 4 Agência Nacional \\ de Saúde Suplementar \\ Rio de Janeiro, Brasil. \\ Correspondência \\ J. C. Lima \\ Escola Nacional de Saúde \\ Pública Sergio Arouca, \\ Fundação Oswaldo Cruz. \\ Rua Benjamim Constant 135 \\ apto. 308, Rio de Janeiro, $R J$ \\ 20241-150, Brasil. \\ julianolima1@aol.com \\ juliano@fiocruz.br
}

\section{Abstract}

This article presents the experience with participatory planning in the Bonsucesso General Hospital in Rio de Janeiro, Brazil, from 2003 to 2004. The participatory and communicative characteristics and the resulting institutional format are identified for guaranteeing the implementation of collective decisions from the planning workshops. The limits of implementation in participatory planning and management proposals are argued from the perspective of change and power relations in these institutions. The results support the notion that projects involving changes in hospitals and failing to take into account the different internal rationalities and power relations end up having reduced potential for implementation.

Planning; Health Planning; Hospital Administration
Juliano de Carvalho Lima 1,2

Ana Cecília Faveret 3,4

Victor Grabois 1,3

\section{Introdução}

O hospital desempenha um papel fundamental nos sistemas de serviços de saúde, pois concentra maior densidade tecnológica e é capaz de dar assistência a casos graves de doenças, sendo geralmente pensado como um ponto de referência do sistema.

O trabalho no interior do hospital é complexo devido à natureza do seu objeto de intervenção (pessoas doentes). A recuperação da saúde dessas pessoas exige uma abordagem integral, o que implica garantir desde o consumo de todas as tecnologias disponíveis para prolongar a vida, até a criação de um ambiente que resulte em conforto e segurança para as pessoas 1 .

No Brasil, os hospitais, em geral, atuam de maneira desarticulada dos demais serviços, principalmente daqueles responsáveis pela atenção primária. Hoje, a ausência de uma rede de atenção primária resolutiva e de um sistema de saúde integrado pressiona os hospitais por meio de uma demanda excessiva em relação à sua capacidade de resposta, gerando filas e mau atendimento.

Garantir a integralidade da atenção no seu interior e a integração à rede de serviços de saúde são desafios colocados para os hospitais. A transformação do hospital, portanto, representa transformações no sistema de saúde. Dentro desta perspectiva o planejamento e a 
gestão destas unidades assumem um papel fundamental e o debate em torno de modelos gerenciais mais adequados às suas especificidades ganha corpo.

No intuito de contribuir para este debate descreve-se a experiência de planejamento do Hospital Geral de Bonsucesso (HGB) em 2003 e 2004, e o sistema de gestão instituído para pôr o plano em prática, tendo em vista as características inovadoras presentes nesse processo. Questões relacionadas às dificuldades de implementação de propostas participativas de mudança nos modos de gerir os hospitais são analisadas sob a perspectiva da mudança e relações de poder nessas instituições.

\section{Métodos}

O HGB é uma unidade hospitalar do Ministério da Saúde, localizado na Cidade do Rio de Janeiro, Brasil, e atende principalmente à população da periferia, além de cidades da Baixada Fluminense. Conta com um conselho de gestão para facilitar sua integração à rede do SUS no estado e com um colegiado de gestão interno.

Trata-se de um complexo hospitalar de caráter terciário, voltado para as áreas cirúrgica, clínica e materno-infantil. É o principal centro de transplantes renais do estado; seu centro de atenção cardiovascular integra as atividades de cardiologia clínica e intervencionista e cirurgia cardíaca; conta com 14 serviços cirúrgicos, dos quais se destacam: cirurgia vascular, neurocirurgia, cabeça e pescoço, oftalmologia, ortopedia e cirurgia geral; sua maternidade é uma das maiores do Rio de Janeiro.

No que diz respeito ao processo em análise (planejamento no HGB), participaram mais de cem pessoas entre profissionais e gerentes. Os objetivos definidos foram: (a) elaborar um plano de ações e metas capaz de orientar a gestão do HGB no período de 2003 a 2006; (b) envolver um conjunto ampliado de atores, incluindo trabalhadores e diretores de unidades; promover maior integração institucional; democratizar o processo de tomada de decisão e; (c) estabelecer mecanismos que possibilitassem verificar a execução dos compromissos assumidos.

Foram realizados, durante os meses de junho a setembro de 2003, mais de 15 encontros, entre oficinas e seminários. Os encontros envolveram a realização de enquetes, discussões de planejamento e análise de textos, além da elaboração de uma proposta de gestão do plano. Durante o ano de 2004 foram implementados mecanismos de gestão do plano.
Para a realização da análise pretendida, primeiramente descreve-se o processo conforme os objetivos explícitos do projeto, tal como veiculados pela Direção durante o período de realização do planejamento. Em seguida, as dificuldades enfrentadas no processo são analisadas sob a perspectiva da gestão participativa, da mudança e das relações de poder no hospital.

\section{Resultados}

Participação e comunicação:

\section{o desenvolvimento da proposta} de planejamento

Duas linhas de intenção foram explicitadas pela direção para a implementação de um planejamento participativo no HGB: organizar ações necessárias para melhorar o serviço prestado, e democratizar a instituição, "mexendo" um pouco com as pessoas. Após um primeiro processo de planejamento em que foram definidos a missão, o perfil e a visão de futuro do Hospital, havia a necessidade de se construir um plano mais detalhado, que chegasse na "ponta". Ao mesmo tempo, havia a intenção por parte da direção de suscitar algum movimento, mexer com algumas concepções arraigadas e superar uma visão incrementalista do Hospital, demonstrando que "se não houver mudança no processo de trabalho, pouco adianta acrescentar estrutura", segundo as palavras do diretor.

Tais intenções apontam para o duplo papel que o planejamento pode desempenhar no âmbito dessas organizações: dispositivo de organização de coletivos para realizar ações para alcançar fins, e dispositivo para a construção de grupos mais autônomos 2 . O planejamento atuaria, portanto, como um espaço virtual de produção de mediação entre várias razões $3 \mathrm{e}$ entre o objetivo e o subjetivo ${ }^{2}$. Para isso, a direção apostou em um processo participativo.

A aposta em um processo participativo de planejamento significa o reconhecimento de que não há homogeneidade de visões a respeito do trabalho no interior do Hospital, de que os resultados do processo não são previsíveis porque há diferentes atores, com distintas intenções, objetivos e interesses.

\section{- 1 passo: definição das linhas estratégicas do HGB}

Para Campos 2, é necessário um deslocamento do planejamento enquanto disciplina, para que este passe a subsidiar grupos humanos para 
formular projetos, e não mais, simplesmente, para elaborar planos de ação.

O projeto é diferente do plano pelo fato de ser o momento em que se dá sentido, diz-se "o que" se deseja. Este teria permanência, enquanto o segundo, o plano, seria provisório e fragmentário. O projeto estaria para o subjetivo assim como o plano estaria para a técnica. Assim, a formulação de projetos seria o momento mais complexo do planejamento, pois seria o momento de constituição do grupo 2 .

Tomou-se o momento da definição das linhas estratégicas do Hospital como o momento da constituição do "projeto". Estas linhas serviriam como balizadoras das discussões nas oficinas, clareando o caminho que se pretendia trilhar. Vale destacar que a primeira demanda da direção era a de elaboração de um plano de ação, o que, aliás, é comum nas organizações: em geral pensa-se em produzir planos antes de se produzirem projetos. $\mathrm{E}$ isto faz toda a diferença no momento da elaboração de um plano coletivamente, pois partir para "o que fazer” é bem mais difícil quando não se sabe "o que se deseja".

Foram realizadas seis reuniões com o grupo de planejamento (grupo de vinte gerentes e profissionais ligados diretamente à direção) para se definir as grandes linhas estratégicas do HGB, que expressassem a missão e o perfil do Hospital. Estas diretrizes foram definidas em função da análise dos pontos fracos internos e em função de novos desafios colocados para a gestão do Hospital, como a inserção do HGB no sistema de saúde e a descentralização da gestão. As linhas estratégicas definidas para o Hospital estão descritas abaixo:

\section{a) Cliente em foco: atendimento integral humanizado e de qualidade}

Trata-se de um tema permeado pela idéia de integração e colaboração 1,4. Duas questões foram colocadas na tentativa de coordenação do cuidado integral e de qualidade: (i) pensar o trabalho em equipe como somatório de ações específicas de cada profissional, tendo a cura como ideal e; (ii) pensar arranjos institucionais que resultem em uma atuação solidária dos trabalhadores envolvidos no cuidado. Isto implica a necessidade de os trabalhadores lançarem mão de dispositivos transdisciplinares que permitam ampliar a qualidade da atenção prestada 1,4 .

\section{b) Profissional em foco: pensando em quem faz}

Esta linha estratégica do Hospital foi definida em torno da discussão de três questões fundamentais: (i) pensar na capacitação permanente destes profissionais, de modo a garantir, simultaneamente, desenvolvimento pessoal e profissional e melhoria do atendimento dos usuários; (ii) pensar a autonomia profissional mediante a inserção dos trabalhadores nos processos de tomada de decisão e; (iii) pensar a satisfação dos profissionais com o seu trabalho.

\section{c) Modelo de gestão: responsabilidade e otimização dos recursos}

A garantia da atenção integral e a garantia da autonomia profissional exigem a organização de mecanismos de gestão que garantam a sua efetivação.

A demanda tem sido por modelos de gestão que garantam a responsabilidade e a otimização dos recursos. Há, portanto, a necessidade de um duplo movimento: (i) compatibilizar maior autonomia com maior capacidade de prestar contas e; (ii) ampliar a rede de compromissos interna com a eficiência e com a transparência. Modelos de gestão centralizadores não garantem à organização a criatividade necessária para que ela tenha maior eficácia e responsabilidade.

Outro desafio da gestão é conseguir coordenar o cuidado integral. Para tanto, é importante rever a divisão interna do trabalho, tradicionalmente apoiada na lógica das profissões, buscando formas alternativas na lógica das unidades de produção e de trabalho em equipe 1,4 .

\section{d) HGB no SUS: regulação e efetiva inserção no sistema}

A multiplicidade de lógicas e de fluxos existentes no sistema de saúde, que não se submetem a uma única racionalidade institucional, põe em xeque a possibilidade de o HGB assumir o perfil definido para si. Há de se buscar maior inserção na rede por meio de uma postura proativa, inclusive no que diz respeito ao acolhimento e à contra-referência, reconhecendo e encaminhando clientes para todos os pontos da rede. É fundamental conhecer as portas de entrada e de saída do Hospital e da rede, de modo a que se possa interferir positivamente na organização das mesmas.

O processo de produção destas linhas estratégicas para o HGB foi bastante rico, mas ficou restrito ao grupo de planejamento, mais 
próximo da direção, não sendo partilhado plenamente com os demais envolvidos.

\section{- 2o passo: realização de enquete}

Tendo por base a experiência descrita por Lima \& Barbosa 5, após a definição das linhas estratégicas, foi realizada uma enquete, no intuito de levantar a percepção dos participantes em relação à situação do HGB. A intenção foi realizar uma primeira análise de situação que subsidiasse as oficinas de trabalho. Foram respondidos 103 questionários. O produto da enquete possibilitou uma visão geral dos problemas relacionados a cada linha estratégica, e foi utilizado para orientar os grupos de trabalho.

No que diz respeito a primeira linha, "o cliente em foco: atendimento integral, humanizado e de qualidade", percebeu-se, por meio da enquete, o pouco uso de instrumentos que permitem maior qualidade na assistência prestada aos usuários, dentre eles a análise de satisfação, análise de óbitos e definição de metas de qualidade. Sessenta e quatro porcento dos que responderam a enquete afirmaram ser raro ou inexistente a análise de satisfação dos usuários no Hospital.

Quanto à integralidade, a percepção dos entrevistados apontou para uma situação complexa. A integração entre os diferentes setores é percebida como sendo insuficiente para $32,4 \%$ dos entrevistados. $\mathrm{O}$ acesso dos usuários aos serviços do HGB e o fluxo desses pacientes internamente receberam nota média igual a $4,9 \mathrm{e}$ 4,6 , respectivamente, o que demonstra a dificuldade que têm os usuários para conseguir respostas às suas demandas.

Foi possível apreender, por meio da percepção dos entrevistados, que o fluxo dos usuários no interior do HGB não é adequado (63,9\% dos entrevistados consideraram este fluxo muito inadequado ou inadequado).

As piores médias, relacionadas à questão da qualidade do atendimento, foram para a qualidade dos registros no Hospital $(4,3)$; o acesso dos usuários a documentos e informações sobre seu tratamento $(4,1)$ e; o tempo de espera dos usuários para serem atendidos $(3,7)$.

$\mathrm{Na}$ outra linha estratégica abordada na enquete, "o HGB no SUS: regulação e efetiva inserção no sistema”, os resultados expressaram uma baixa integração com os demais serviços da Área 3.1 e com o município. A maior parte dos serviços atende a uma demanda espontânea, não referenciada, não realiza contra-referência, não tem rotinas e protocolos estabelecidos para atendimento dos casos prioritários e atendem indistintamente casos de baixa e al- ta complexidade. Os principais mecanismos de relação com a rede de serviços são informais, com base em conhecimentos pessoais.

Outros resultados apontam problemas para o HGB assumir concretamente o perfil definido para si: $39 \%$ dos que responderam a enquete identificaram serviços no HGB que poderiam ou deveriam se constituir como referência mas que ainda não o são, e $24 \%$ identificam serviços que deveriam ser abandonados ou reformulados.

Em relação à linha estratégica "o profissional em foco", a enquete revelou que dentre os elementos importantes para se elevar a satisfação e a motivação e manter o vínculo dos profissionais no HGB, encontram-se a instituição de premiação por tempo de serviço e a eliminação das formas precárias de contratação.

Por fim, em relação ao "modelo de gestão", a enquete não forneceu elementos capazes de subsidiar a discussão. No entanto, a auto-avaliação quanto à capacidade gerencial dos serviços ficou em 6,3.

Dentre os itens que podem ajudar a melhorar a gerência houve um apontamento claro para a importância de uma estrutura gerencial que conjugue mais de um profissional de saúde, assessorados por um gerente profissional.

\section{- 3o passo: elaboração de textos de apoio}

Partindo do pressuposto de que a compreensão acerca da situação do Hospital e das suas linhas estratégicas não era homogênea, e que isso imporia limites para o planejamento, decidiu-se elaborar textos de apoio para dar subsídios às discussões. Foram produzidos três textos: o primeiro, Antecedentes do Processo Atual de Planejamento, teve por objetivo resgatar o processo histórico do Hospital e de seu planejamento. O segundo, intitulado Linhas Estratégicas do $H G B$, trazia uma discussão sintética acerca das quatro linhas estratégicas outrora definidas no âmbito da direção. Utilizou-se como base textos que abordam a instituição hospitalar e sua gestão, com destaque para autores como Cecílio ${ }^{1}$ e Cecílio \& Merhy ${ }^{4}$. O último texto foi intitulado A Organização Hospitalar e Modelos de Gestão, e procurou debater as principais características das organizações hospitalares, apoiando-se em autores como Braga Neto 6, Mintzberg 7, Barbosa 8, Cecílio ${ }^{9}$ e Rivera \& Artmann 10. Este texto foi o único debatido com todos os participantes.

A avaliação é de que os textos desempenharam papel importante, pois, permitiram em algum grau, esclarecer do que se estava tratando por integralidade, inserção no SUS, modelo de 
gestão, conceitos que perpassaram as oficinas. No entanto, os textos utilizados no planejamento do HGB poderiam ser mais bem explorados a fim de permitir maior compartilhamento com os participantes.

Neste sentido, a proposta de Campos 11 acerca da articulação entre informação, texto, análise e práticas no cotidiano da gestão dos serviços poderia balizar uma utilização diferenciada dos textos produzidos para o planejamento do HGB. Nesta proposta, "os termos Escuta, Observação e Leitura indicam a capacidade de se produzir informações e signos e de compô-los em um Texto que é posto em análise para que daí resultem tomadas de decisão, a definição de tarefas, e a progressiva composição de um Projeto" 11 (p. 198).

\section{- 4o passo: oficinas de planejamento}

A metodologia de planejamento adotada tentou, ao mesmo tempo, conjugar a riqueza do processo, caracterizada pela democratização das discussões e envolvimento de novos atores, com a efetividade do resultado, caracterizada pela construção de um plano capaz de fornecer ao Hospital maior clareza dos objetivos a serem atingidos e os meios a serem empregados para tal. Por isso, optou-se por uma adaptação do Planejamento Estratégico Situacional (PES) 12, que propõe uma tecnologia de intervenção na realidade que reconhece a existência de vários atores que planejam e admite a análise da realidade como situacional.

Para Barbosa 8 (p. 145), “hoje, em saúde, as concepções teóricas e metodológicas do planejamento mais disseminadas e assumidas no País como mais avançadas, podem ser referenciadas em torno do planejamento estratégico situacional (PES) e de suas diversas aproximações".

Adotou-se na prática uma variante comunicativa do PES 13, incluindo várias técnicas para constituir espaços dialógicos e com flexibilidade metodológica. Atentou-se principalmente para a viabilidade do plano, a fim de evitar a construção de um plano fora de qualquer possibilidade de execução.

Ao todo foram realizadas 12 oficinas de trabalho, incluindo quatro grandes seminários, entre os dias 15 de julho e 30 de setembro. Os encontros foram semanais e ocorreram na parte da manhã. O processo seguiu os seguintes momentos:

a) Realização de reunião ampliada preparatória com os atores envolvidos (com todos os participantes), visando a: resgatar o processo e apresentar os produtos dos momentos anteriores, explicitar o processo a ser desenvolvido, realizar discussões a partir de questões relacionadas ao papel do Hospital e ao papel de cada um no seu interior, organizar os grupos transversais de acordo com as linhas estratégicas do HGB para o desenvolvimento das oficinas de planejamento estratégico.

Esse momento foi fundamental para um bom andamento dos trabalhos, pois situou os envolvidos no processo. Além disso, partiu-se do pressuposto de que a tecnologia de planejamento a ser adotada não é de domínio de todos, havendo necessidade de uma certa "calibração". b) Oficinas de planejamento com base no PES (adaptado), partindo do levantamento de problemas por linhas estratégicas, seguindo os seguintes passos por linha estratégica: Passo 1 levantamento dos problemas; Passo 2 - descrição dos problemas; Passo 3 - definição de resultados; Passo 4 - desenho das estratégias; Passo 5 - definição das metas; e Passo 6 - definição dos prazos e responsáveis.

As oficinas de planejamento ocorreram em encontros semanais, em turno único para evitar o cansaço e permitir maior participação. Elas foram realizadas em dois blocos. No primeiro bloco foram abordadas as linhas estratégicas 1 e 4 - "O Cliente em Foco: Atendimento Integral Humanizado e de Qualidade" e "HGB no SUS: Regulação e Efetiva Inserção no Siste$m a$ ". No segundo foram abordadas as Linhas 2 e 3 - "O Servidor em Foco: Pensando em Quem Faz" e "Modelo de Gestão: Responsabilidade e Otimização dos Recursos”.

\section{Da formulação à ação:} o modelo de gestão do plano

A vivência de outras experiências de planejamento participativo vinha demonstrando que, apesar do envolvimento das pessoas no momento da elaboração do plano, este, com grande freqüência, não era implementado. Ou seja, apesar de se adotar um método sistemático, de tornar o processo democrático, permeá-lo à participação, isto, por si só, não garantia a implementação do plano.

Desde o início do processo chamou-se a atenção dos participantes de que o fundamental seria o desenvolvimento do plano e que este seria realizado também por um grupo ampliado (o mesmo que participou de sua elaboração). Este argumento tinha por objetivo desfazer a idéia bastante comum de que os planos não dão certo porque o método é inadequado; fazer ver que, independente das técnicas utilizadas para a construção de um plano, o fundamental para sua implementação é a disposição das pessoas que o elaboraram. 
O modelo de gestão do plano no HGB parte da compreensão de gestão enquanto um processo político de produzir contratualidades entre os diferentes atores 14 .

Assim sendo, sugeriu-se um sistema de gestão do plano organizado em espaços de gestão (rodas). A idéia de Rodas de Gestão aponta para o fortalecimento e responsabilização das pessoas e a democratização da instituição como meios para superar a racionalidade gerencial de orientação taylorista. Ao mesmo tempo, faz alusão a espaços flexíveis e em movimento, passíveis de revisão o tempo todo 11 . A proposta de gestão do plano do HGB visou a dar conta de dois componentes principais: um processo de conformação das decisões cotidianas, e o acompanhamento da execução e dos impactos das estratégias. Tornou-se necessária a institucionalização destes espaços, tendo isto sido definido em conjunto com a direção do Hospital.

Foram constituídas as seguintes Rodas de Gestão do Plano:

a) Roda 1: coordenação geral de desenvolvimento do plano; responsável pela condução global do processo e pela coordenação do sistema de prestação de contas. Constituída por quatro pessoas, envolvendo o diretor, a vice-diretora e dois assessores de planejamento.

b) Roda 2: grupos de acompanhamento por macroobjetivos; têm por função agregar os responsáveis por cada estratégia referente ao macroobjetivo e acompanhar o desenvolvimento das ações conforme cronograma definido em conjunto com a coordenação geral (Roda 1). Possui líderes e responsáveis. Os Líderes desempenham as seguintes funções: (i) facilitam e acompanham o processo de implementação das estratégias; (ii) promovem a integração entre os responsáveis, identificando ações afins; (iii) promovem a integração entre os responsáveis pelas estratégias e as chefias dos setores; (iv) prestam contas da situação do macroobjetivo ao colegiado ampliado de discussão; (v) distribuem as estratégias com os Responsáveis. Estes, por sua vez, possuem as seguintes atribuições: são encarregados diretos pela implementação das estratégias e prestam contas da situação de cada uma. Ao todo são quatro grupos de acompanhamento por macroobjetivos. c) Roda 3: colegiado ampliado de discussão; composto pelo conjunto dos participantes da elaboração do plano, tem por função discutir a situação do desenvolvimento do plano e propor novas diretrizes para a sua execução. É o espaço de petição e prestação de contas.

Essas Rodas possuem a seguinte dinâmica: há reuniões regulares (mensais) entre a Roda 1 e os líderes da Roda 2 (entre a coordenação ge- ral e os líderes dos grupos de acompanhamento por macroobjetivos). Ao todo são quatro Rodas de acompanhamento, cada uma possui quatro líderes, responsáveis por entre quatro a cinco macroobjetivos. O número de responsáveis é variável, de acordo com o número de estratégias. As reuniões entre os líderes dos macroobjetivos e os responsáveis são livres, dependendo da dinâmica adotada por cada grupo. No entanto, a coordenação geral (Roda 1) estimula que também haja no mínimo uma reunião mensal. As reuniões do colegiado ampliado (Roda 3) é quadrimestral. Nestas reuniões, os líderes de cada grupo de acompanhamento (Roda 2) prestam contas do andamento das estratégias.

Esse arranjo instituído no HGB possibilitou um certo grau de democratização da instituição quanto à execução real do plano.

\section{- Componentes do sistema} de acompanhamento e avaliação

Para facilitar o acompanhamento das atividades inerentes ao desenvolvimento do Plano, a Coordenação organizou uma espécie de banco de dados para armazenar informações oriundas dos demais grupos (Tabela 1).

\section{- Indicadores de acompanhamento e avaliação}

Ao se estabelecer este sistema de gestão do plano, duas tarefas fundamentais são acompanhar e avaliar. Para tanto, deve haver o estabelecimento de indicadores globais, capazes de fornecer uma visão sistêmica tanto da implementação quanto do resultado das estratégias definidas no plano.

Os indicadores foram elaborados com base nas discussões nas oficinas de planejamento, porém, sofreram modificações após revisão pela equipe de apoio ao planejamento. Os indicadores construídos até o momento estão descritos na Tabela 2:

Conforme destacado inicialmente, a marca do processo implementado no HGB em 2003/ 2004 foi a participação. Era evidente a expectativa de que a partir da participação seria possível dar maior capacidade operativa ao plano e gerar novas práticas (mudança), mais alinhadas com um determinado projeto para o Hospital. A seguir discutem-se as principais dificuldades encontradas nesse processo. 
Descrição dos elementos que constituem o sistema de acompanhamento da implementação do plano do Hospital Geral de Bonsucesso, Rio de Janeiro, Brasil.

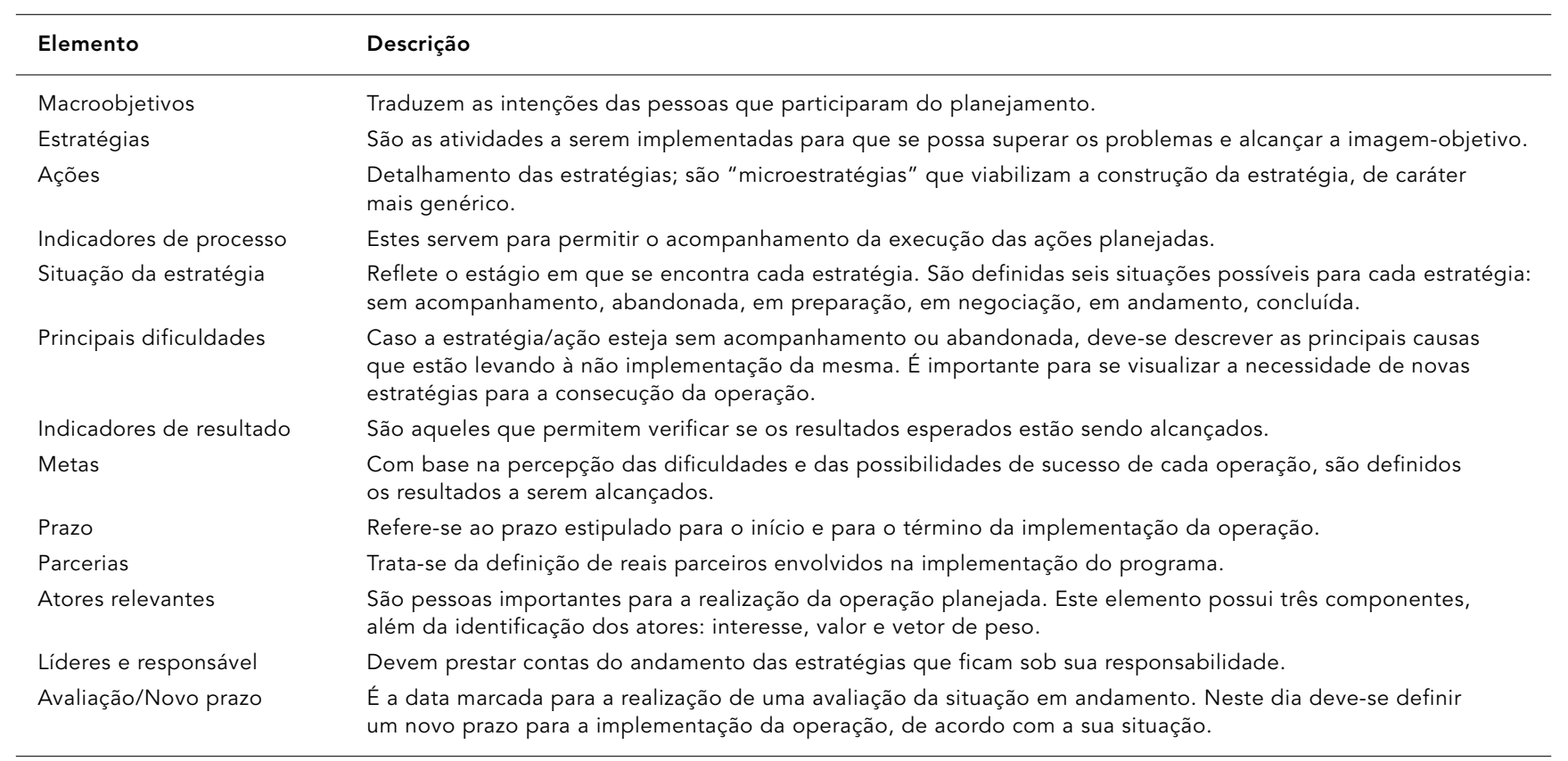

\section{Discussão}

Segundo Motta 15, a idéia de participação na teoria gerencial tem origem na análise de dois fatores inerentes ao meio organizacional: o conflito e a cooperação, com destaque para o primeiro.

O desenvolvimento de uma concepção das organizações como sistemas pluralistas de poder acentua a noção de que as organizações são constituídas por uma diversidade de interesses de grupos e de indivíduos. "Na visão pluralista, indivíduos e grupos internos possuem interesses e lutam para que os efeitos das decisões internas lhes sejam favoráveis" 15 (p. 157).

Concomitante ao desenvolvimento dessa concepção, deu-se uma transformação no modo de se olhar o conflito no interior das organizações. Aquilo que era considerado uma "disfuncionalidade" a ser aniquilada, passa a ter a sua funcionalidade reconhecida, ou seja, o conflito passa a ser visto positivamente, inclusive como portador de um potencial para contribuir para o progresso organizacional.

A participação, considerada no sentido amplo como as formas e meios pelos quais os membros de uma organização podem influenciar os destinos dessa organização, então surge como um instrumento para a cooperação e pa- ra a solução de conflitos: "a participação é normalmente considerada uma forma eficaz de solução, acomodação ou equilíbrio entre grupos divergentes" 15 (p. 159). Outro benefício creditado a processos participativos de gestão pela Teoria Organizacional é a "desalienação": “ $a$ participação desaliena indivíduos e destrói paroquialismos e percepções distorcidas sobre o uso do poder" 15 (p. 159).

A direção do HGB fez uma aposta na possibilidade de implementação de um processo participativo de planejamento e de gestão, com os objetivos explícitos de implementar mudanças que resultassem, simultaneamente, na melhoria dos serviços prestados e na democratização da instituição, gerando processos de reflexão e novas práticas.

No entanto, questões relativas às particulares relações de poder no Hospital e às conseqüentes restrições a projetos de mudança foram pouco consideradas, o que resultou na incapacidade de implementação plena da proposta de gestão do plano.

Nas organizações hospitalares, a fonte principal do conflito tem origem na multiplicidade de atores, profissões e racionalidades existentes no seu interior 16, e se expressam em uma série de "pares de opostos" descritos por Cecílio 1. Destes pares de opostos, destacam-se duas 
Indicadores de acompanhamento e avaliação do plano do Hospital Geral de Bonsucesso, Rio de Janeiro, Brasil.

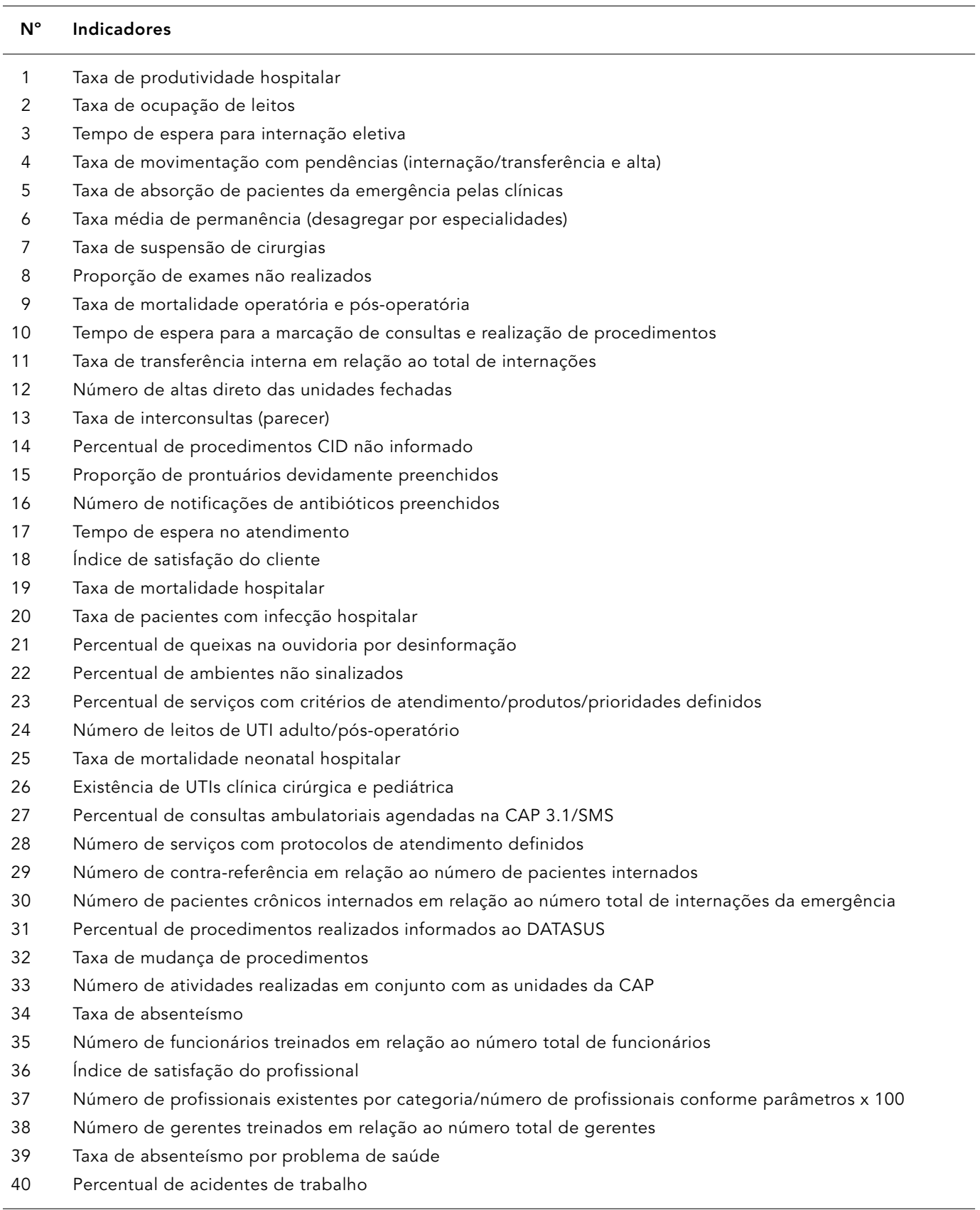

antinomias: o alto grau de especialização e autonomia dos profissionais versus a necessidade de coordenação do trabalho e da organização; e o poder técnico concentrado nos profissionais da organização versus o poder administrativo da direção 1 .

Assim, há, no Hospital, um duplo sistema de autoridade. Uma primeira linha descenderia da administração até o pessoal hospitalar, obedecendo a um rígido esquema hierárquico e centralizado. A segunda linha é decorrente do poder saber dos médicos 17 que lhes permite confrontar a administração na luta pela defesa de seus interesses profissionais. Os profissionais gozam de grande autonomia, decorrente de seu saber especializado e da complexidade de seu trabalho, por isso, não admitem influências 17. A autonomia é a grande fonte de poder 
dos profissionais, que vão tentar controlar a organização para manterem o poder sobre as decisões que possam afetar suas práticas 9 .

Sob essa perspectiva, a aposta em um processo participativo de planejamento e gestão, quando adotado do ponto de vista da direção, pode ser também compreendido como uma tentativa, por parte do poder administrativo, de gerenciar a grande autonomia dos profissionais. Este objetivo, embora não explicitado, estava presente na proposta implementada no HGB. Tanto que a definição das linhas estratégicas, que orientaram todo o desenvolvimento do processo de planejamento, se deu no círculo mais próximo da direção.

Desse modo, assume-se a direção do HGB como um ator que reconhece a existência de outros atores, autônomos, com objetivos que não são necessariamente os seus e que aposta na participação como um mediador das várias racionalidades e interesses visando, além da maior eficácia, eficiência e democratização, ao gerenciamento da autonomia no Hospital.

O processo de planejamento e o arranjo instituído para garantir a operacionalização do plano elaborado provocaram um movimento sem precedentes no HGB. A presença constante de aproximadamente cem pessoas com formação e inserção diferentes no Hospital nas oficinas de planejamento pode dar um indicativo da riqueza das atividades desenvolvidas. $\mathrm{O}$ arranjo institucional montado para gerir o plano (rodas de gestão, sistema de monitoramento, indicadores) mostrou-se, inicialmente, promissor para a implementação das atividades previstas.

No entanto, uma série de dificuldades se impôs para a implementação da proposta, dentre as quais, pode-se citar: (i) a pouca participação dos médicos; (ii) a inoperância das Rodas de Gestão; (iii) a dificuldade de relacionamento entre as Rodas de Gestão (líderes dos grupos de acompanhamento) e as chefias dos vários setores do Hospital, gerando conflitos; (iv) a dificuldade para implementação dos indicadores e da sistemática de avaliação; (v) a dificuldade para compor Equipes de Apoio aos Grupos com pessoal experiente na área de gestão hospitalar e; (vi) a abertura de outras frentes de trabalho, com perda do foco no Plano.

Considera-se que as principais dificuldades foram a pouca participação dos profissionais e a resistência para romper com a estruturação da gestão e do trabalho centrada na lógica da hierarquia de poder intra e intercorporações, uma vez que estas duas dão origem à maior parte das demais dificuldades. Gerou-se uma disputa silenciosa entre os Líderes de algumas das Rodas de Gestão e os chefes dos setores, que resultaram na não implementação de várias ações que exigiam, de fato, trabalho conjunto.

Deve-se ainda destacar que o conteúdo do plano, em virtude da maior participação nas oficinas do pessoal ligado à direção, tinha forte componente de mudança, com propostas de implementação de processos que influenciariam diretamente a prática médica e as chefias dos setores, como por exemplo, a criação de unidades de atenção por nível de cuidado, a proposta de centralização do gerenciamento dos leitos na admissão, a implantação do sistema de vigilância hospitalar, dentre outros.

Cecílio 1,9 tem chamado a atenção para as dificuldades de implementação de propostas democráticas de gestão nos hospitais. O autor credita boa parte dos fracassos dos processos de implementação de mudanças nos hospitais às particularidades das relações de poder existentes, e trabalha com a hipótese de que a não adesão dos profissionais, particularmente dos médicos, aos novos modelos de gestão se deve ao fato de que esses profissionais estariam vendo essas propostas como uma tentativa de controlar suas práticas, sendo vivenciadas, paradoxalmente, como estratégias centralistas.

As mudanças que vêm sendo propostas na área da gestão em saúde 4,11,13, se implementadas de fato, têm potencial para subverter as relações de poder existentes nos serviços de saúde em geral, e nos hospitais em particular. Quando propostas pela direção, como é o caso do HGB, esses mecanismos participativos podem resultar, paradoxalmente, no aumento de poder da direção e de outros atores que estão na parte de baixo da balança do poder no Hospital, uma vez que colocam em discussão temas anteriormente decididos exclusivamente pelos profissionais e pelas chefias. A participação efetiva quebra as barreiras que isolam as várias corporações, setores e profissionais.

Daí a resistência dos médicos e das chefias, e a necessidade de um olhar mais cuidadoso, no momento de implementação dessas propostas, sobre as relações de poder existentes e as "cotas" de poder dos vários atores (médicos, enfermeiros, direção, chefes de setores...).

É fundamental ter em conta que o poder, como relação estruturada, assim como se encontra nos hospitais, passa a se cristalizar e vai constituindo a cultura de um grupo 18. Portanto, a mudança na gestão do Hospital é um processo cultural. Segundo Motta 15, quando valores fundamentais são ameaçados tendem a gerar reação (que pode ser a não participação), uma vez que as mudanças geram quebras de 
relações e padrões estabelecidos no ambiente de trabalho. No caso, leia-se quebras nos padrões de relações de poder estabelecidas.

De fato, as relações de poder parecem ser o cerne das discussões sobre a mudança nos hospitais. "A dispersão do poder faz com que a inovação se torne um problema difícil de ser conduzido, em virtude das inúmeras linhas de influência" 15 (p. 235).

Para Moliani 16 (p. 63), "o fato de o hospital contar com um conjunto de locais e de profissionais com suas próprias racionalidades, formas de funcionamento e modos de compreender a finalidade da organização coloca seus membros numa situação de conflito permanente, pois a convergência dessa multiplicidade de racionalidades nada tem de espontânea".

Daí que é possível compreender boa parte das dificuldades para a implementação das Rodas de Gestão no HGB, pois estão em disputa lógicas distintas de organizar o processo de gestão, estruturadas por problemas de um lado, e de acordo com a hierarquia das corporações (chefia médica, chefia de enfermagem...) e das estruturas (chefias de laboratório, chefia da radiologia...) por outro.

Por isso, Cecílio ${ }^{9}$ (p. 325) afirma que não deixa de ser uma certa idealização "supor que a gestão colegiada, no sentido de se garantir que todos os trabalhadores tenham direito a voz e voto, nas unidades de trabalho, seja garantia do surgimento automático de um sujeito coletivo capaz de conduzir a unidade de forma autôno$m a "$, como se supunha no HGB.

Assim, em ambientes como o hospitalar, com as características particulares de relações de poder, as potencialidades inerentes à participação devem ser relativisadas. A solução dos conflitos pode não ser alcançada pelo simples fato de os principais atores no Hospital, os médicos, não participarem. A idéia um tanto arrogante de "desalienação" deve ser repensada em função do reconhecimento da existência de projetos em disputa, decorrentes das diferentes maneiras que os atores visualizam a finalidade da organização e as propostas de mudança na gestão, e de como elas afetam suas práticas (autonomia).

Por fim, os resultados encontrados na experiência do HGB corroboram discussões feitas por Cecílio 1,9 de que projetos de mudança que não levem em conta as distintas racionalidades existentes no interior do Hospital e as particulares relações de poder acabam por ter reduzido o seu potencial de implementação.

\section{Resumo}

O presente artigo apresenta a experiência de planejamento participativo realizado no Hospital Geral de Bonsucesso, Rio de Janeiro, Brasil, nos anos de 2003 e 2004. Destacam-se o caráter participativo e comunicativo da experiência e os arranjos institucionais formulados para garantir a implementação do que fora decidido coletivamente nas oficinas de planejamento. Discutem-se os limites da implementação de propostas participativas de planejamento e gestão sob a perspectiva da mudança e relações de poder nessas instituições. Reforça-se a idéia de que projetos de mudança no Hospital que não levem em conta as distintas racionalidades e as relações de poder existentes no seu interior acabam por ter reduzido o seu potencial de implementação.

Planejamento; Planejamento em Saúde; Administração Hospitalar

\section{Colaboradores}

J. C. Lima foi responsável pela elaboração da proposta metodológica e pela discussão do artigo. V. Grabois e A. C. Faveret participaram da elaboração da Introdução e da apresentação dos Resultados. 


\section{Referências}

1. Cecílio LCO. Mudar modelos de gestão para mudar o hospital: cadeia de apostas e engenharia de consensos. Revista Espaço para a Saúde 2002: 1:4-26.

2. Campos RO. O planejamento no labirinto. Uma viagem hermenêutica. São Paulo: Editora Hucitec; 2003.

3. Rivera FJU. Agir comunicativo e planejamento social: uma crítica ao enfoque estratégico. Rio de Janeiro: Editora Fiocruz; 1995.

4. Cecílio LCO, Merhy EE. A integralidade do cuidado como eixo da gestão hospitalar. In: Pinheiro R, Mattos RA, organizadores. Construção da integralidade: cotidiano, saberes e práticas em saúde. Rio de Janeiro: Instituto de Medicina Social, Universidade do Estado do Rio de Janeiro/ABRASCO; 2003. p. 197-210.

5. Lima SML, Barbosa PR. Planejamento e inovação gerencial em um hospital público: o caso do Hospital Municipal Salgado Filho. Revista Brasileira de Administração Pública 2001; 35:37-76.

6. Braga Neto F. Examinando alternativas para a administração dos hospitais: os modelos de gestão descentralizados e por linha de produção [Dissertação de Mestrado]. Rio de Janeiro: Escola Nacional de Saúde Pública, Fundação Oswaldo Cruz; 1991.

7. Mintzberg H. Criando organizações eficazes. Estruturas em cinco configurações. São Paulo: Editora Atlas; 1995.

8. Barbosa PR. Gestão em saúde: o desafio dos hospitais como referência para inovações em todo o sistema de saúde. In: Fleury S, organizadora. Saúde e democracia, a luta do CEBES. São Paulo: Lemos Editorial; 1997. p. 143-62.
9. Cecílio LCO. Autonomia versus controle dos trabalhadores: a gestão do poder no hospital. Ciênc Saúde Coletiva 1999; 4:315-29.

10. Rivera FJU, Artman E. A gestão situacional (em saúde) e a organização comunicante. Cad Saúde Pública 1996; 12:357-72.

11. Campos GWS. Um método para análise e co-gestão de coletivos. São Paulo: Editora Hucitec; 2000.

12. Matus C. Política, planejamento e governo. Brasília: Instituto de Pesquisa Econômica Aplicada; 1997.

13. Rivera FJU. Análise estratégica em saúde e gestão pela escuta. Rio de Janeiro: Editora Fiocruz; 2003.

14. Merhy EE. Um dos grandes desafios do SUS: apostar em novos modos de fabricar os modelos de atenção. In: Merhy EE, organizador. O trabalho em saúde: olhando e experienciando o SUS no cotidiano. São Paulo: Editora Hucitec; 2003. p. 15-36.

15. Motta PR. A ciência e a arte de ser dirigente. Rio de Janeiro: Record; 2002.

16. Moliani MM. Especialização e compartimentalização de saberes: efeitos sobre a produção de cuidados e administração em saúde. Revista FAE 2000; 3:61-74.

17. Foucault M. Microfísica do poder. Rio de Janeiro: Graal; 1990.

18. Roso A, Bueno SN, Guareschi P. Planejamento na área da saúde: o poder em discussão. Saúde Debate $2000 ; 24: 38-53$.

Recebido em 03/Ago/2004

Versão final reapresentada em 25/Jul/2005

Aprovado 14/Set/2005 